\title{
Post-Anastomotic Enterocutaneous Fistulas: Associated Factors and Spontaneous Closure at a Tertiary Centre in Western Kenya
}

\author{
Musau P. MBChB, MMed, Msc (Urol), Jumbi G., MBChB, MMed, FCS (ECSA), Parklea P. MBChB, MMed, FCS (ECSA). Affiliation: \\ Moi Teaching and Referral Hospital, Eldoret. Correspondence: Dr. P. Musau, MTRH, P.0. Box 5455-30100, Eldoret. E-mail: pius_ \\ musau@yahoo.com
}

\section{Abstract}

\section{Objective}

To determine the factors associated with the occurrence and spontaneous closure of enterocutaneous fistulas.

Design

A retrospective, hospital-based study of patients who developed enterocutaneous fistulas after resection and anastomosis.

Setting

The general and paediatric surgical wards of Moi Teaching and Referral Hospital (MTRH), a 550 bed tertiary teaching and referral hospital in the Western region of Kenya.

Subjects

Two hundred and twenty patients of all ages who underwent gut resection and anastomosis for varied reasons between 2002 and 2006.

\section{Main outcome measures}

The primary outcome measures were variables associated with development and spontaneous closure of fistulas while the secondary outcome measures were morbidity and mortality associated with enterocutaneous fistulas.

Results

Enterocutaneous fistulas formed in 22 of 220 patients and constituted $44 \%$ of all the complications after gut resection and anastomosis. Age younger than 20 years $(p=0.04)$, female gender $(p=0.032)$, duration of symptoms greater than one day prior to presentation to hospital $(0.032)$, deranged electrolytes $(p=0.042)$, delay in surgery after admission ( $p=0.043$ ) and the use of ileal segment in the anastomosis $(p=0.018)$ were significantly associated with occurrence of fistulas on univariate analysis. The use of ileal segment in the anastomosis $(p=0.033)$, deranged electrolytes $(p=0.045)$ and duration prior to surgery $(p=0.045$ ) were also found to be predictive of fistula formation on multivariate analysis.

The spontaneous closure rate was $45.5 \%$. Factors significantly associated with spontaneous closure were age greater than 20 years ( $p=$ $0.027)$ and occurrence of the fistula in an ileal segment $(\mathrm{p}=0.031)$. Enterocutaneous fistulas had a case specific mortality rate of $50 \%$.The factor most significantly associated with mortality was re-operation $(\mathrm{P}<0.001)$ and this was also predictive of both mortality and prolonged hospital stay.

\section{Conclusion}

Renal dysfunction, delay before surgery and the use of ileal segments were significantly associated with the occurrence of enterocutaneous fistulas while age greater than 20 years and occurrence of fistulas in ileal segments had significant association with spontaneous closure of the fistulas. Re-operation is a strong predictor of mortality in enterocutaneous fistula patients.

\section{Introduction}

Enterocutaneous fistulas cause significant morbidity and mortality and can challenge even the most experienced surgeon (1). In the developed countries, most fistulas are due to Crohn's disease (2) but may also arise to postoperatively (3). Historically, when enterocutaneous fistulas developed, less than half closed spontaneously $(4,5)$ but presently, a significant number of them can be successfully managed without re-operation (6). Spontaneous closure is only possible in an environment in which sepsis is controlled and distal bowel obstruction eliminated $(5,7)$.

Mortality in enterocutaneous fistulas is dependent on

the interventions before, during and after surgery (8). Early and sound surgical decisions, preoperative optimisation of the patient, meticulous surgery based on sound principles and adequate postoperative care would minimise the morbidity and mortality associated with this common surgical complication.

Moi Teaching and Referral Hospital (MTRH) is the main referral facility for the Western Kenya region. The pattern and experience with the management of enterocutaneous fistulas in the centre remain unknown. This study evaluated the factors associated with fistula formation after gut resection and anastomosis and explored those related to spontaneous closure of the fistulas. 
Post-Anastomotic Enterocutaneous Fistulas: Associated Factors and Spontaneous

Closure at a Tertiary Centre in Western Kenya Musau P., Jumbi G., Parklea P.

\begin{tabular}{lllllll} 
COMPLICATION & \multicolumn{9}{l}{ AGE IN YEARS } & & TOTAL \\
\hline & $0-20$ & $21-40$ & $41-60$ & $61-80$ & $>80$ & \\
\hline wound infection & 4 & 3 & 3 & 1 & 1 & 12 \\
\hline burst abdomen & 2 & 1 & 2 & 2 & 0 & 7 \\
\hline Fistula & 14 & 4 & 4 & 0 & 0 & 22 \\
\hline anastomotic leak & 2 & 0 & 1 & 0 & 0 & 3 \\
\hline Others & 2 & 3 & 0 & 0 & 1 & 6 \\
\hline not applicable & 51 & 49 & 42 & 23 & 5 & 170 \\
\hline TOTAL & 75 & 60 & 52 & 26 & 7 & 220
\end{tabular}

Table 1: Complications and age of patient

\begin{tabular}{llllll} 
COMPLICATION & \multicolumn{3}{c}{ TYPE OF ANASTOMOSIS } & & TOTAL \\
\hline & ileoileal & ileocolic & colocolic & multiple & \\
\hline wound infection & 5 & 5 & 1 & 1 & 12 \\
\hline burst abdomen & 3 & 2 & 2 & 0 & 7 \\
\hline Fistula & 14 & 6 & 2 & 0 & 22 \\
\hline anastomotic leak & 3 & 0 & 0 & 0 & 3 \\
\hline Others & 3 & 3 & 0 & 0 & 6 \\
\hline not applicable & 60 & 45 & 57 & 8 & 170 \\
\hline TOTAL & 88 & 61 & 62 & 9 & 220 \\
\hline
\end{tabular}

Table 2: Type of anastomosis versus complications

\section{Materials And Methods}

This was a retrospective hospital based analysis of patients who underwent gut resection and anastomosis in the 550 bed tertiary hospital between 2002 and 2006 .

A research assistant retrieved the files from the medical records department and abstracted the following data: demographics, type and duration of symptoms, vital signs at admission, laboratory results on renal function and full haemogram, resuscitative interventions, duration from admission to surgery, intra-operative findings and degree of peritoneal soiling, postoperative complications, re-operative interventions, duration of hospital stay and the outcome of management with reference to discharge or death.

Case notes with inadequate information were excluded. A total of 30 files were on this basis excluded from analysis and 220 incorporated into the study.

Data was coded and entered into spreadsheets and subsequent storage in the computer using Statistical Package for Social Sciences software version 12.0 that was used for the analysis.

Decision to operate was based on the primary problem for which abdominal surgery was indicated. There was no standard protocol for the operative management of enterocutaneous fistulas except for the broad guidelines on the daily output of the fistula and presence of peritoneal soiling or infection.

Variables were analyzed in keeping with the primary and secondary outcome measures for descriptive and inferential statistics with significance levels less than 0.05 and a confidence interval of 95\%. Age, sex, duration of symptoms, vital signs at admission, laboratory investigations, duration prior to surgery, intra-operative findings, type of anastomosis, presence of complications, re-operative surgery and outcome of treatment were all subjected to univariate and multivariate analyses.

\section{Results}

Two hundred and twenty patients of varied ages were analysed. The ages ranged from 2 days to 94 years; mean $34 \pm 24$ years. The male: female ratio was 2.5:1.

Fifty patients (22.7\%) developed post-anastomotic complications. Twenty-two of these (44\%) complications were enterocutaneous fistulas (tables 1 and 2).

The majority $(63.6 \%)$ of the fistulas formed in those aged 0-20 years. At univariate analysis, the following factors were significantly associated with the development of enterocutaneous fistulas: age less than 20 years $(\mathrm{p}=0.040)$, female gender $(\mathrm{p}=0.032)$ symptoms duration of more than 24 hours prior to presenting to hospital (0.032), electrolyte derangement ( $p=0.045)$, use of ileum in the anastomosis $(\mathrm{p}=0.018)$ and intra-hospital delay prior to surgery ( $\mathrm{p}=0.043$ ) (Table 3$)$. The patient's clinical state at admission, pre-operative resuscitation and the cadre of surgeon involved were not significantly associated with likelihood of fistula formation. The majority $(68.2 \%)$ of the fistulas developed in patients found to have peritoneal soiling during surgery but there was no statistical difference on further analysis.

On linear regression only abnormal laboratory results of 
urea, creatinine and electrolytes $(\mathrm{p}=0.045)$ and use of ileal segment $(\mathrm{p}=0.048)$ predicted the development of fistulas.

The overall re-operation rate for complications was 50\%; least in wound infections (16.7\%) and a rate of $54.5 \%$ in patients with fistulas. This give spontaneous fistula closure rate of $45.5 \%$. Spontaneous fistula closure was significantly associated with age $(\mathrm{p}=0.027)$ and type of anastomosis done $(\mathrm{p}=0.031)$. Patients older than 20 years had spontaneous closure of their fistulas 1.5 times as often as those younger than 20 years. The patients with ileal surgery closed spontaneously 1.4 times as often as those who had colonic anastomosis. Table 4 shows the variables and their association with spontaneous fistula closure on univariate analysis.

The majority (77.2\%) of patients with fistulas stayed beyond two weeks. Re-operation was a greater predictor of prolonged hospital stay than the existence of fistula (P value $<0.001$ vs. 0.004 ) on linear regression analysis (Table 5).

Enterocutaneous fistulas carried a case specific mortality rate of $50 \%$ compared to $10 \%$ among those who did not develop complications and $15.9 \%$ overall mortality rate in the study group. While presence of a fistula was correlated with outcome ( $\mathrm{p}=0.006)$, it had no predictive value. Reoperation was a strong predictor of mortality $(\mathrm{p}<0.001)$ (Table 5).

\section{Discussion}

The occurrence of enterocutaneous fistulas after abdominal surgery remains a dreadful complication with challenges on how best to manage them. They are a common occurrence as seen in this study where it formed $44 \%$ of the complications that arose after gut resection and anastomoses.

A number of factors were found to contribute to fistula formation. Age of the patient, renal dysfunction, duration prior to surgery and use of ileal segments in

\begin{tabular}{|c|c|c|c|c|}
\hline \multicolumn{4}{|c|}{ Variable } & \multirow[t]{2}{*}{$\mathrm{p}$ value } \\
\hline \multicolumn{4}{|c|}{ Duration prior to hospital presentation } & \\
\hline Formed & $<24 \mathrm{hrs}$ & >one day & Total & \\
\hline Yes & 3 & 19 & 22 & \\
\hline No & 8 & 190 & 198 & 0.032 \\
\hline \multicolumn{5}{|l|}{ Age } \\
\hline Formed & Up to 20 yrs & $>20 y r s$ & Total & \\
\hline Yes & 14 & 8 & 22 & \\
\hline No & 61 & 137 & 198 & 0.040 \\
\hline \multicolumn{5}{|l|}{ Gender } \\
\hline Formed & Male & Female & Total & \\
\hline Yes & 9 & 13 & 22 & \\
\hline No & 149 & 49 & 198 & 0.032 \\
\hline \multicolumn{5}{|c|}{ Vital signs } \\
\hline Formed & Normal & Deranged & Total & \\
\hline Yes & 7 & 15 & 22 & \\
\hline No & 69 & 129 & 198 & 0.430 \\
\hline \multicolumn{5}{|c|}{ Preoperative resuscitation } \\
\hline Formed & Yes & No & Total & \\
\hline Yes & 21 & 1 & 22 & \\
\hline No & 193 & 5 & 198 & 0.955 \\
\hline \multicolumn{5}{|c|}{ Laboratory U/E results } \\
\hline Formed & Normal & Deranged & Total & \\
\hline Yes & 6 & 16 & 22 & \\
\hline No & 98 & 100 & 198 & 0.042 \\
\hline \multicolumn{5}{|c|}{ Duration prior to surgery } \\
\hline Formed & Within 6 hrs & $>6 \mathrm{hrs}$ & Total & \\
\hline Yes & 2 & 20 & 22 & \\
\hline No & 22 & 176 & 198 & 0.043 \\
\hline \multicolumn{5}{|l|}{ Surgeon } \\
\hline Formed & Medical Officer & Consultant & Total & \\
\hline Yes & 7 & 15 & 22 & \\
\hline No & 50 & 148 & 198 & 0.526 \\
\hline \multicolumn{5}{|c|}{ Intra-operative findings } \\
\hline Formed & Gangrene & Peritonitis & Total & \\
\hline Yes & 7 & 15 & 22 & \\
\hline No & 76 & 122 & 198 & 0.520 \\
\hline \multicolumn{5}{|c|}{ Type of anastomosis } \\
\hline Formed & Ileal & Colonic & Total & \\
\hline Yes & 20 & 2 & 22 & \\
\hline No & 129 & 69 & 198 & 0.018 \\
\hline
\end{tabular}

Table 3: Enterocutaneous Fistula Formation the antomosis were associated with fistula formation while ileal segments and renal dysfunction were independent predictors for fistula formation. This is 
Post-Anastomotic Enterocutaneous Fistulas: Associated Factors and Spontaneous

Closure at a Tertiary Centre in Western Kenya Musau P., Jumbi G., Parklea P.

Variable

Duration prior to hospital presentation

\begin{tabular}{lllll}
\hline Closure & $<24 \mathrm{hrs}$ & >one day & Total & \\
\hline Re-operated & 0 & 12 & 12 & \\
\hline Spontaneous & 1 & 9 & 10 & 0.521 \\
\hline
\end{tabular}

Age

Closure

Re-operated

Spontaneous

Gender

Re-operated

Spontaneous

Vital signs

Closure

Re-operated

Spontaneous

Preoperative resuscitation

\section{Closure}

Re-operated

Spontaneous

Laboratory U/E results

\begin{tabular}{lllll}
\hline Closure & Normal & Deranged & Total & \\
\hline Re-operated & 4 & 8 & 12 & \\
\hline Spontaneous & 3 & 7 & 10 & 0.098 \\
\hline Duration prior to surgery & & & & \\
\hline Closure & Within $\mathbf{~ h r s ~}$ & $\mathbf{7 6 \text { hrs }}$ & Total & \\
\hline Re-operated & 0 & 12 & 12 & \\
\hline Spontaneous & 2 & 8 & 10 & 0.133 \\
\hline
\end{tabular}

\section{Surgeon}

Closure

Re-operated

Spontaneous

Intra-operative findings

\begin{tabular}{lllll}
\hline Closure & Gangrene & Peritonitis & Total & \\
\hline Re-operated & 5 & 7 & 12 & \\
\hline Spontaneous & 3 & 7 & 10 & 0.420 \\
\hline Type of anastomosis & & & & \\
\hline Closure & Ileal & Colonic & Total & \\
\hline Re-operated & 10 & 2 & 12 & \\
\hline Spontaneous & 9 & 1 & 10 & 0.031 \\
\hline
\end{tabular}

Table 4: Spontaneous Closure Of Fistulas

in keeping with the findings by Fry that technical difficulties during surgery and co morbid factors contribute to fistula formation (9). In this study, the greatest determinant of fistula formation was the use of an ileal segment in the anastomosis. This might be explained by the likely presence of greater degree of peritoneal soiling with peritonitis and friability of tissues leading to technical difficulties during anastomosis especially in those with pre-surgical delays in excess of 24 hours after admission.

Gender seems to be associated with fistula formation due to the effect of other factors. More females than males had abnormal vital signs at admission besides having a lower percentage of preoperative resuscitation and more cases of peritoneal soiling. These other compounding factors could explain the higher numbers of females having enterocutaneous fistulas.

Patients with long delays before seeking medical attention presented in decompensated physiological states at admission with deranged vital signs and renal dysfunction and were operated on by consultants after stabilisation. In the inferential analysis, there was no significant association between the expertise of the surgeon and fistula formation.

The spontaneous closure of fistulas in this study was $45.5 \%$. Kuvshinoff et al reported spontaneous closure of less than fifty percent (4) while Howard and colleagues specifically found it to be $32 \%$ (5). The differences may be due to the time when the studies were done and the lack of standardisation of the types of fistulas in the studies. Surgical intervention is recommended in high output fistulas, in presence of infections and where conservation would lead to excessive hospital stay $(1,2,5,10,11)$. Alfonso and colleagues had a re-operative rate of $71 \%$ (3) and this could be an indication that there is a greater tendency towards conservative management in our setting. Age greater than 20 years and ileal segment in the anastomosis were found to be associated with spontaneous closure of fistulas. These findings point to luminal calibre and the different healing capacities of intestinal 


\section{VARIABLE AND DURATION OF HOSPITAL STAY}

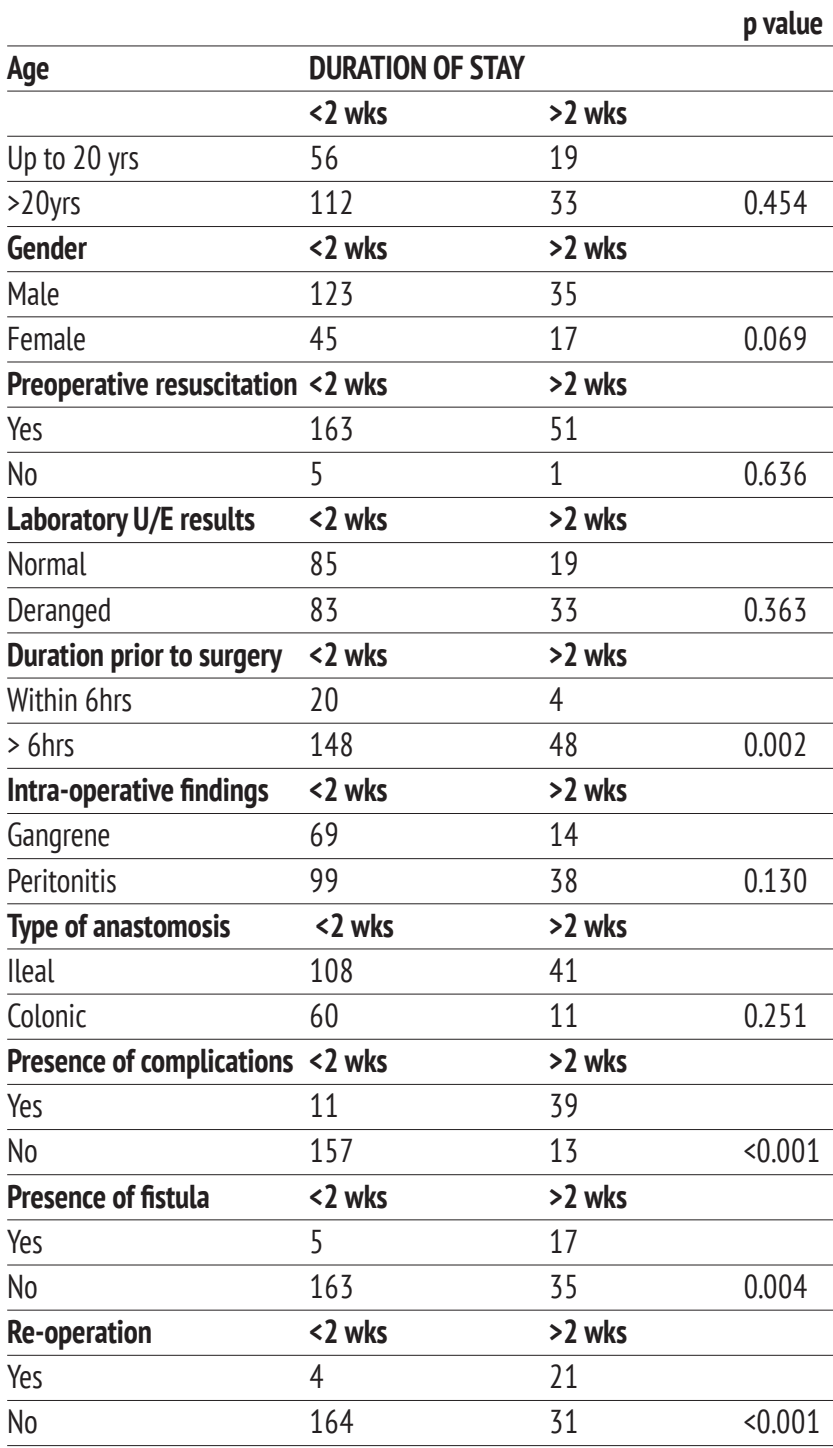

Table 5: Select Factors, Hospital Stay And Mortality

segments as factors to be considered when making a decision on conservative management in enterocutaneous fistulas besides the amount of enteral contents lost in the output per day.

The presence of a fistula led to lengthy stay in the ward and was related to mortality. Re-operative surgery was also a predictor of both prolonged stay and mortality following fistula formation. These are findings that had also been noted in other studies $(3,5)$. The findings might also explain the dilemma surgeons face

\section{VARIABLE AND MORTALITY}

\begin{tabular}{|c|c|c|c|}
\hline & & & p value \\
\hline Age & OUTCOME & & \\
\hline & Lived & Died & \\
\hline Up to 20 yrs & 56 & 19 & \\
\hline$>20 \mathrm{yrs}$ & 129 & 16 & 0.071 \\
\hline Gender & Lived & Died & \\
\hline Male & 137 & 21 & \\
\hline Female & 48 & 14 & 0.091 \\
\hline Preoperative resuscitation & Lived & Died & \\
\hline Yes & 180 & 34 & \\
\hline No & 5 & 1 & 0.959 \\
\hline Laboratory U/E results & Lived & Died & \\
\hline Normal & 90 & 14 & \\
\hline Deranged & 95 & 21 & 0.350 \\
\hline Duration prior to surgery & Lived & Died & \\
\hline Within 6hrs & 18 & 6 & \\
\hline$>6 \mathrm{hrs}$ & 167 & 29 & 0.425 \\
\hline Intra-operative findings & Lived & Died & \\
\hline Gangrene & 70 & 13 & \\
\hline Peritonitis & 115 & 22 & 0.183 \\
\hline Type of anastomosis & Lived & Died & \\
\hline Ileal & 118 & 31 & \\
\hline Colonic & 67 & 4 & 0.031 \\
\hline Presence of complications & Lived & Died & \\
\hline Yes & 3218 & & \\
\hline No & 153 & 17 & $<0.001$ \\
\hline Presence of fistula & Lived & Died & \\
\hline Yes & 11 & 11 & \\
\hline No & 174 & 24 & 0.006 \\
\hline Re-operation & Lived & Died & \\
\hline Yes & 15 & 10 & \\
\hline No & 170 & 25 & $<0.001$ \\
\hline
\end{tabular}

when dealing with enterocutaneous fistulas and the preference for conservative management in this study. In conclusion, renal dysfunction, delay before surgery and the use of ileal segments were significantly associated with the occurrence of enterocutaneous fistulas while age greater than 20 years and occurrence of fistulas in ileal segments had significant association with spontaneous closure of the fistulas. Re-operation is a strong predictor of mortality in enterocutaneous fistula patients. 


\section{Acknowledgement}

To Henry Mwangi for being a good Research Assistant, the Director Moi Teaching and Referral Hospital for allowing publication of this study and Angeline Chepkorir Musau for the splendid secretarial work.

\section{References}

1. Craig AL, Conor PD, Anthony JS et al. Clinical outcome and factors predictive of recurrence after enterocutaneous fistula surgery. Ann Surg 2004; 240(5): 825-831.

2. Michelassi F, Stella M, Balestracci $T$ et al. Incidence, diagnosis and treatment of enteric and colorectal fistulae in patients with Crohn's disease. Ann Surg 1993; 218(5): 660-666.

3. Alfonso A, Josef EF, Claude EW. The role of surgery and hyperalimentation in therapy of gastrointestinal-cutaneous fistulae. Ann Surg1974; 180(4): 393-400.

4. Kuvshinoff BW, Brodish RJ, McFadden DW et al. Serum transferrin as a prognostic indicator of spontaneous closure and mortality in gastrointestinal cutaneous fistulas.
Ann Surg1993; 217(6): 615-623.

5. Howard AR, Carl R, Lawrence W et al. Management of external gastrointestinal fistulas. Ann Surg1978; 188(4): 460-466.

6. Neil H, Thomas LM, Turner $\mathrm{O}$ et al. Anastomotic leaks after anastomosis: it is later than you think. Ann Surg 2007; 245(2):254-258.

7. Maconi G, Parente F, Porro G. Hydrogen peroxide enhanced ultrasound-fistulography in the assessment of enterocutaneous fistulas complicating Crohn's disease. Gut 1999; 45(6):874-878.

8. Soeters PB, Ebeid AM, Fischer JE. Review of 404 patients with gastrointestinal fistulas: Impact of parenteral nutrition. Ann Surg 1979; 190(2): 189 - 202.

9. Fry DR. Enterocutaneous fistula. J R Soc Med 1997; $90(8): 471$.

10. Hawker PC, Givel JC, Keighley MR et al. Management of enterocutaneous fistulae in Crohn's disease. Gut 1983; 24(4):284-287.

11. David MS, Trevor CW, Alexander-Williams J. Abscess and fistulae in Crohn's disease. Gut1973; 14(11):865-869. 